\title{
Study on the evolution law of density current in the Xiaolangdi Reservoir before the flood in 2018
}

\author{
Li Xinjie $^{1,2}$, Wang Yuanjian ${ }^{1,2^{*}}$, Qu Shaojun ${ }^{1,2}$, Wang Ting ${ }^{1,2}$, Li Kunpeng ${ }^{1,2}$ \\ ${ }^{1}$ Yellow River Institute of Hydraulic Research, Zhengzhou 450003, China \\ ${ }^{2}$ Key Laboratory of Yellow River Sediment Research, MWR, Zhengzhou 450003, China \\ Author: Li Xinjie )1977-( , Dengzhou, Henan, Senior Engineer, Doctor's Degree, Specialized in sedimentation and reservoir \\ management. \\ Wang Yuanjian, Senior Engineer, Doctor's Degree. Specialized in reservoir sediment and river dynamics.
}

\begin{abstract}
Sediment problems affect the operation life and comprehensive benefits of a reservoir. In response to the floods in the middle and upper reaches of the Yellow River, the Xiaolangdi Reservoir is subjected to preventative pre-discharge scheduling. Through a prototypical observation of the density current plunging zone of the Xiaolangdi Reservoir in 2018, we collected prototypical data of the water level, water-sediment characteristics, sediment thickness, thalweg points, and flow velocity, and analyzed the pre-dam distribution of density current and scouring-sedimentation characteristics during the flood dispatching period of the Xiaolangdi Reservoir. The research results promoted the understanding of the movement law of the density current of the Xiaolangdi Reservoir and the development of efficient sediment drainage technology for reservoirs.
\end{abstract}

\section{Introduction}

The Xiaolangdi Reservoir is a large-scale waterconservancy hub built primarily for the prevention of water floods (also the prevention of ice-jam floods) and reduction of sedimentation in addition to water supply, irrigation, and power generation, and it plays an important strategic role in the management and development of the lower Yellow River [1]. The water-sediment dispatching of the Yellow River is designed to make full use of the floods of the upper and middle reaches and the reservoir capacity while fully considering the sediment transport capability of the lower rivers, so as to allow a timely discharge for adjusting the natural water-sediment process and make the uncoordinated water-sediment process become coordinated as much as possible, thereby facilitating the sediment to be transported into the sea.

The NHL National Hydraulics Laboratory, Chatou, France conducted a systematic study on the various characteristics of density current. The turbid density current venting phenomenon in China was first observed in the Guanting Reservoir in 1953. Since then, China has gradually conducted research on this type of phenomenon and has obtained many research results. Through joint reservoir scheduling in the middle reaches of the Yellow River, Li Guoying et al. artificially created density current in the Xiaolangdi Reservoir and achieved high-efficiency sediment removal from the reservoir [2]. Li Tao, et al. provided an overview on the research progress of the conditions of density current plunging, head movement speed of density current, interface resistance, sediment transport law, and the research methods [3]. Based on previous studies, Li Shuxia, et al. [4] investigated how density current occurs and moves as well as how it transports sediment by analyzing the field observation data of density current in the Xiaolangdi Reservoir in conjunction with analyzing relevant physical models and water tank test results, and qualitatively summarized the conditions of density current plunging in reservoirs, presented quantitative calculation methods, and proposed a new discriminant formula for the conditions of density current plunging, with the formula calibrated and validated based on multiple indoor and field measurement data sets in 2012[5]. Based on a model test in the construction period of the Xiaolangdi Reservoir, Zhang et al. revealed that the early sediment-retaining period of the reservoir was characterized by turbid density current venting, and that the plunging point was generally located at the front slope in the lower reach of the delta apex with the plunging conditions conforming to the general law [6]. Based on the data in 2001, Hou et al. analyzed densitycurrent-induced water-sediment characteristics as well as changes and influencing factors of plunging point in the Xiaolangdi Reservoir, preliminarily establishing a

*Corresponding author: E-mail: wangyuanjian@hky.yrcc.gov.cn E_mail:xin_wd@163.com 
relationship formula to describe the transport capacity of density current in the reservoir [7]. Li Xiangyang, et al. analyzed the relationship among the thickness of density current, flow rate of density current, flow velocity of density current, and sediment concentration of density current by analyzing the prototypical observation data of the Xiaolangdi Reservoir region in 2014 [8]. It is of great significance to provide forecasting services for the Xiaolangdi Reservoir to discharge the maximum amount of sediment at optimal sediment discharging time during the density current period. When regulating water and sediment, the authority primarily takes advantage of turbid density current venting to achieve high-efficiency removal of sediment. Therefore, it is necessary to conduct prototypical observation of density current to gain a timely understanding of its movement law to provide technical support for developing a water-sediment control plan and evaluating its performance.

During the pre-flood period of 2018 (July 1 to July 12), heavy rain occurred in the middle reaches of the Yellow River and in the Weihe River Basin. According to the sedimentation pattern of the Xiaolangdi Reservoir region in 2017 [9], the authority conducted joint scheduling of reservoirs to successfully reduce the water level of the Xiaolangdi Reservoir and achieve turbid density current venting. This study aimed at conducting a prototypical observation of density current of the Xiaolangdi Reservoir in a pre-flood period and analyzing the pre-dam situation of water scouring and sediment discharging to provide technical support for high-efficiency sediment removal from the Xiaolangdi Reservoir in the future.

\section{Density current monitoring}

\subsection{Layout of monitoring sections}

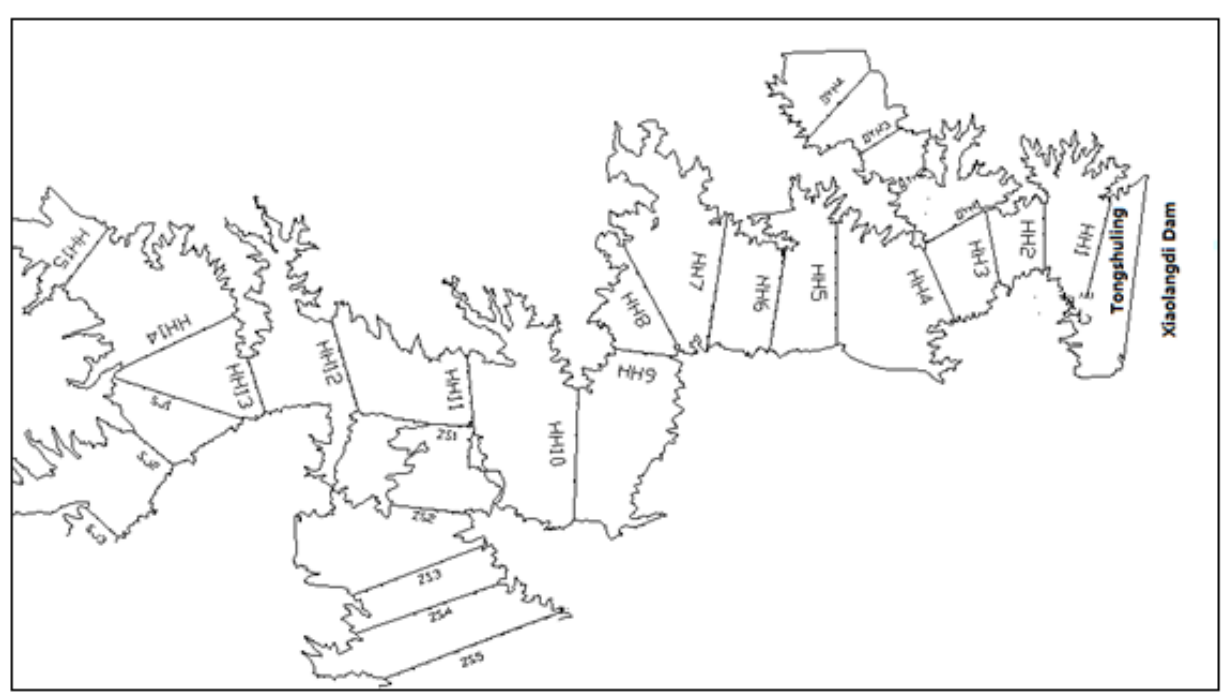

Fig.1. Layout of the density current monitoring sections in 2018

\subsection{Situation of reservoir operation}

Sediment discharge from the Xiaolangdi Reservoir is primarily achieved via turbid density current venting at present. By dropping the abutting water level, sediment
To fully track the evolution process of density current in front of the dam, three basic sediment monitoring sections and multiple streamline monitoring sections were established in the Xiaolangdi Reservoir region, as shown in Figure 1[3]. The monitoring was conducted via a combination of the cross-sectional method and the streamline method according to the following measurement principle: 1) controlling the whole process of changes in the water and sediment such as the plunging, moving, and disappearing of density current, and 2) laying out monitoring lines and sites to control the changes in the thickness, flow velocity, and sediment concentration of density current at the monitoring sections along the flow path. The density current observation scheme in 2018 included the following parts: basic sediment monitoring sections were composed of the sections $\mathrm{HH} 01, \mathrm{HH} 04$, and $\mathrm{HH} 07$; streamline monitoring sections were composed of the sections $\mathrm{HH} 03, \mathrm{HH} 05$, and HH06 as well as the section containing the plunging point. The actual monitoring section of the plunging point (zone) moved up or down according to the water level fluctuation in the reservoir. Density current was measured from July 4 to July 12, and the full evolution process of density current was monitored at each section.

The development process of density current in a reservoir is composed of three different geographical zones in the reservoir-the plunging zone, intra-reservoir evolution zone, and pre-dam zone [8]. After the openchannel flow of sediment-laden water enters the reservoir, it is converted to density current near the plunging point. Identification of the plunging point of density current and analysis of the influencing factors of plunging point locations are essential for studying the law of density current. 
At 8:00 am on July 1, the water level of the Xiaolangdi Reservoir was $229.81 \mathrm{~m}$, the water storage capacity was 1.01 billion $\mathrm{m}^{3}$, and the water discharge rate was 1,030 $\mathrm{m}^{3} / \mathrm{s}$. Subsequently, the water discharge rate was increased, reaching the maximum value of $4,090 \mathrm{~m}^{3} / \mathrm{s}$ at 8:00 pm on July 13 when the water level dropped to $211.77 \mathrm{~m}$ and the water storage capacity decreased to 200 million $\mathrm{m}^{3}$, as shown in Figure 2.

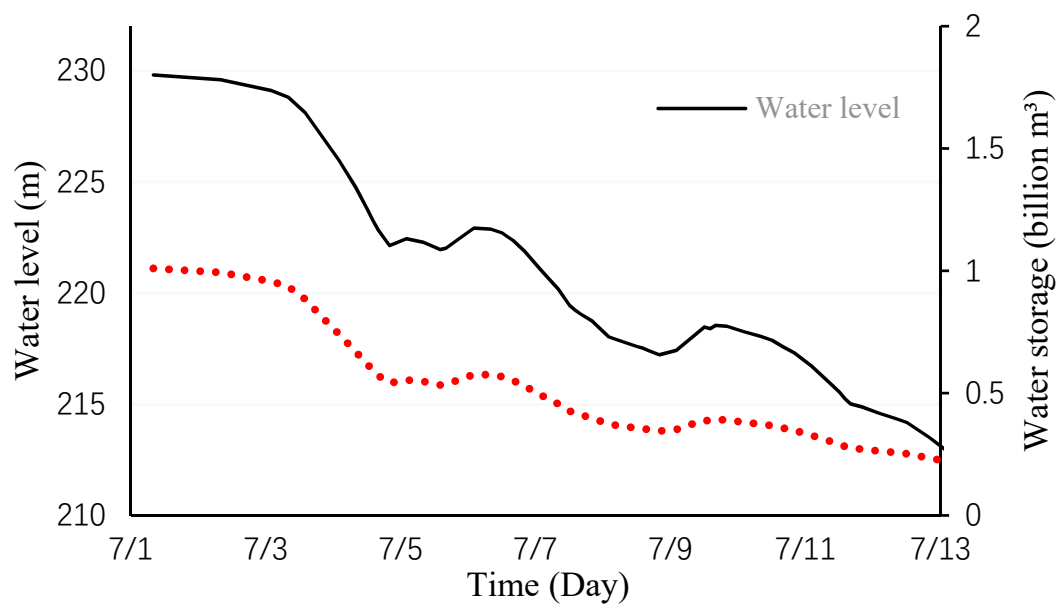

Fig.2. Curve of water level of the Xiaolangdi Reservoir

\subsection{Water-sediment process of the reservoir}

To cope with floods from the main stream and its tributary Weihe River, the Sanmenxia Reservoir and the Xiaolangdi Reservoirs are subjected to preventative predischarge scheduling. Water was discharged from the Sanmenxia Reservoir in advance. At 7:24 pm on July 3, the water level at the Sanmenxia hydrographic station began to rise with a flow rate of $1,390 \mathrm{~m}^{3} / \mathrm{s}$, and the flow rate increased to $1,460 \mathrm{~m}^{3} / \mathrm{s}$ at $20 \mathrm{pm}$ and reached a peak value of $2,060 \mathrm{~m}^{3} / \mathrm{s}$ at 11:24 $\mathrm{pm}$. Flood peak discharge occurred on July 5 , reaching a flow rate of $4,060 \mathrm{~m}^{3} / \mathrm{s}$. On July 6 , flood peak discharge occurred in Tongguan with a flow rate of $2,580 \mathrm{~m}^{3} / \mathrm{s}$. The discharge of the Xiaolangdi Reservoir began to rise at 2:00 am on July 3 with a flow rate of $1,680 \mathrm{~m}^{3} / \mathrm{s}$, and the flow rate continually increased to $3,000 \mathrm{~m}^{3} / \mathrm{s}$ at $10: 18 \mathrm{pm}$ on the same day and eventually to the peak value of $4,090 \mathrm{~m}^{3} / \mathrm{s}$ at 9:00 am on July 7 . The prototypical observation of the discharge process of the Sanmenxia Reservoir and the Xiaolangdi Reservoir is illustrated in Figure 2. After July 12, floods continued in the main stream and tributaries of the Yellow River in its middle reaches and the daily mean rate of the Sanmenxia hydrographic station was still approximately $3,000 \mathrm{~m}^{3} / \mathrm{s}$, generating density current and sediment discharge in the Xiaolangdi Reservoir. By 20 pm on July 13, the water level of the Xiaolangdi Reservoir dropped to the minimum value of $211.77 \mathrm{~m}$, making the reservoir water highly turbid while density current was still ongoing, as shown in Figure 3.

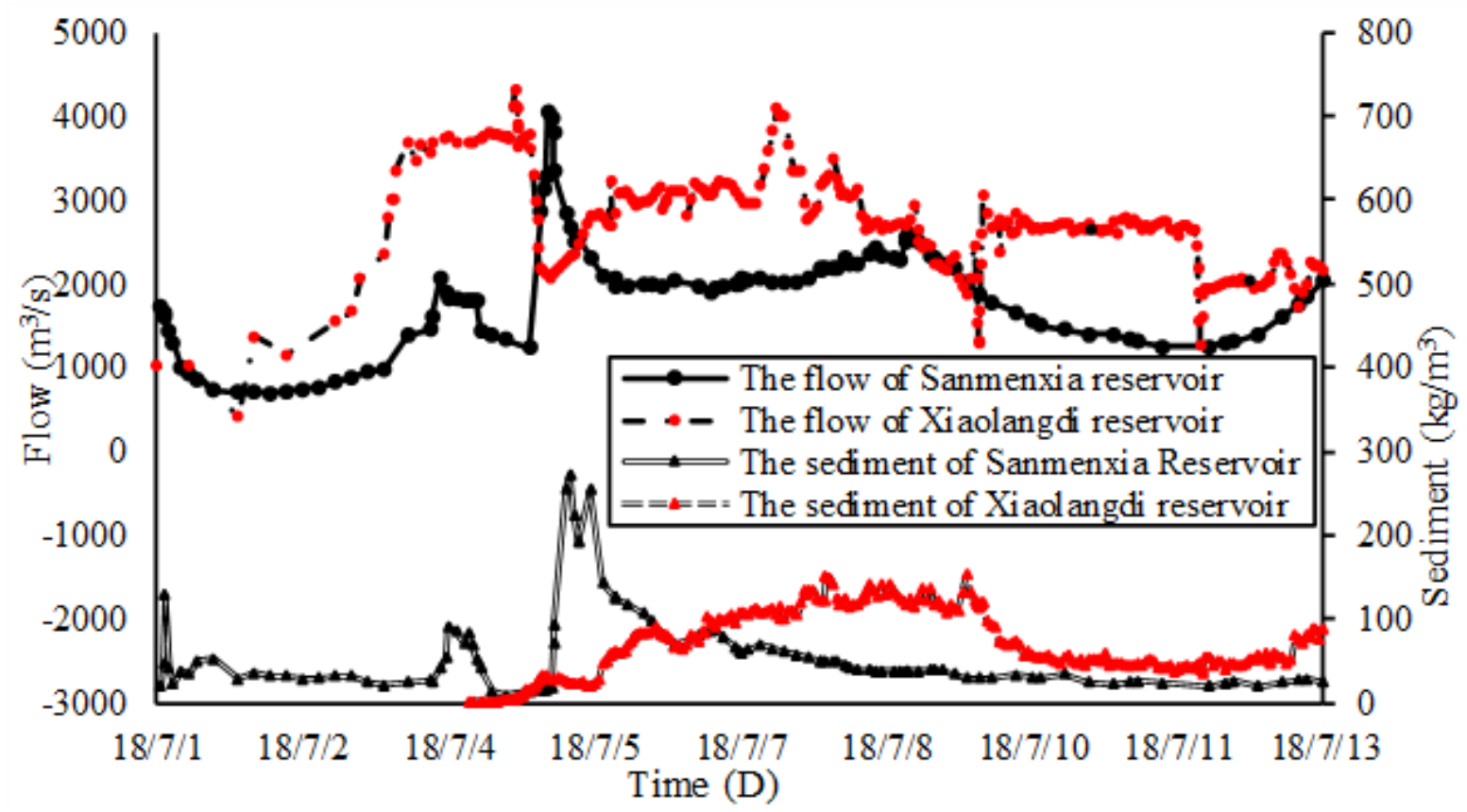

Fig.3. Water-sediment discharge process of the Sanmenxia and Xiaolangdi Reservoirs in 2018

\subsection{Monitoring of density current}

From 8:00 pm on July 3 to $8: 00 \mathrm{pm}$ on July 4, the maximum sediment concentration of the Sanmenxia Reservoir during the discharge period was $92.3 \mathrm{~kg} / \mathrm{m}^{3}$ 
(2:00 am on July 4), and a flood peak appeared on July 5 with a maximum daily sediment concentration of 147.4. $\mathrm{kg} / \mathrm{m}^{3}$.

The highly sediment-laden water discharged from the Sanmenxia Reservoir scoured the riverine sediments when moving toward the lower reaches and eventually scoured the sediments in the backwater zone of the Xiaolangdi Reservoir, which increased the sediment concentration in the water flow and formed density current at the end of the backwater zone of the Xiaolangdi Reservoir. At 8:43 am on July 4, density current plunging was detected at a water depth of $10.6 \mathrm{~m}$ at the HH07 section of the Xiaolangdi Reservoir, and the current had a muddy water thickness of $5.70 \mathrm{~m}$ with the maximum flow velocity of $0.39 \mathrm{~m} / \mathrm{s}$ and the maximum sediment concentration of $5.04 \mathrm{~kg} / \mathrm{m}^{3}$ among the monitoring sites, indicating that the sediment concentration was small. On July 9 , the maximum daily sediment concentration of the Xiaolangdi Reservoir reached $154 \mathrm{~kg} / \mathrm{m}^{3}$, and density current was plunging near the dam with a density current thickness of $0.84 \mathrm{~m}$ according to the evaluation criterion of density current thickness in the Xiaolangdi Reservoir.

In practice, sediment-laden density current occurred earlier than the observation time points in this study. The sediment content at the Xiaolangdi hydrographic station was $1.38 \mathrm{~kg} / \mathrm{m}^{3}$ at 6 am on July 4 . According to the time and distance with respect to the station, it was estimated that the density current plunged in the reservoir at around 2:00 am on July 4 whereas turbid density current venting from the reservoir occurred at around 5:30 am.

During this density current period, owing to the low water level of the Xiaolangdi Reservoir, the plunging point was close to the dam. Moreover, given the long flood duration of the upper reaches, water and sediment were continuously input to the reservoir, resulting in density current that lasted for a long time with a high intensity. As the water level continued to decline, the highly sediment-laden water flow from the upper reaches continued to enter the reservoir, which almost turned the reservoir into a fully turbid one. The thickness of the clear water layer at the Tongshuling monitoring section (HH01) - a section before the dam-was as small as $3 \mathrm{~m}$ (which was observed at a monitoring site named horizontal 4-1 (main 7) on the section at 7:30 am on July $7,1,100 \mathrm{~m}$ from the initial site).

At the $\mathrm{HH} 07$ section, the maximum thickness of density current was $15.9 \mathrm{~m}$, the maximum average sediment concentration of density current was $271 \mathrm{~kg} / \mathrm{m}^{3}$, and the maximum flow velocity was $2.99 \mathrm{~m} / \mathrm{s}$; at the HH04 section, the aforementioned three values were 20.2 $\mathrm{m}, 166 \mathrm{~kg} / \mathrm{m}^{3}$, and $2.73 \mathrm{~m} / \mathrm{s}$, respectively; at the $\mathrm{HH} 01$ section, they were $27.5 \mathrm{~m}, 78.9 \mathrm{~kg} / \mathrm{m}^{3}$, and $2.04 \mathrm{~m} / \mathrm{s}$, respectively.

\section{Changes in density current along the path}

\subsection{Propagation speed of density current}

At around 2 am on July 4, density current plunged at the HH07 section of the Xiaolangdi Reservoir, $8.96 \mathrm{~km}$ from the dam; by 5:30 am, when turbid density current venting occurred, the density current had moved for approximately $3.5 \mathrm{~h}$ in the reservoir with a propagation speed of approximately $0.71 \mathrm{~m} / \mathrm{s}$.

Statistical analysis indicated that the maximum flow velocity of density current was large at each section. The maximum flow velocity at a single measuring point was $2.04 \mathrm{~m} / \mathrm{s}$ on July 5, and the maximum depth-averaged flow velocity was $0.63 \mathrm{~m} / \mathrm{s}$ (HH01); the maximum flow velocity at a single measuring point was $2.99 \mathrm{~m} / \mathrm{s}$ (HH07) on July 8 whereas the flow velocity at a single measuring point was $2.73 \mathrm{~m} / \mathrm{s}$ at both HH04 and HH06, and the maximum depth-averaged flow velocity of the sections was $1.23 \mathrm{~m} / \mathrm{s}$, with the maximum value being $1.02 \mathrm{~m} / \mathrm{s}$ at HH06; on July 9, the maximum depth-averaged flow velocity was $1.24 \mathrm{~m} / \mathrm{s}$ (HH07). As the energy loss of density current was small in the plunging process, the current still had a large flow velocity.

The elevation of the lowest points of the main stream of the Yellow River in 2018 is shown in Figure 4.

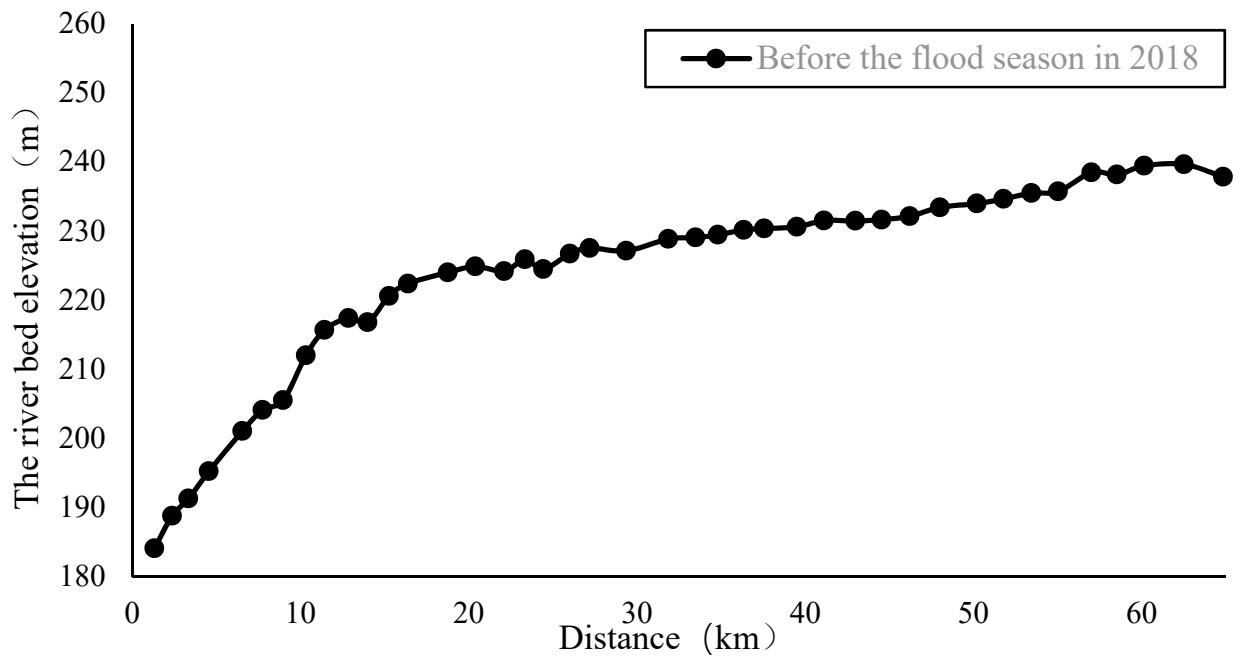

Fig.4. Elevation of the thalweg points of the main stream in the Xiaolangdi Reservoir in the pre-flood period of 2018 
Based on the above figure, the river bed gradients between the sections in the downstream of the plunging point were calculated. From $\mathrm{HH} 37$ to $\mathrm{HH} 11$, the river bed gradient was approximately $0.37 \%$, and the elevation of the thalweg points was 222.4-239.6 m; from HH11 to HH07 (the plunging point), the river bed gradient was $2.27 \%$, but the elevation of the thalweg points was $205.5-$ $222.4 \mathrm{~m}$; the river bed gradient was $2.27 \%$ from the downstream section of the plunging point to the section $\mathrm{HH} 04$ and was $3.47 \%$ from $\mathrm{HH} 04$ to $\mathrm{HH} 01$.

During the density current process, owing to the low water level of the reservoir, the density current plunged at positions close to the dam (HH07 section) with a high flow velocity, and as it propagated, the density current was subject to resistance along the flow path. Given that the river bed gradient in the region between the plunging point and the dam was all above $2 \%$, the density current plunging into the region could propagate quickly with high flow velocity, thereby facilitating sediment discharge from the reservoir.

\subsection{Evolution process of density current}

The density current in this study was affected by the incoming water, the water level in the reservoir, and the sedimentation pattern in the reservoir. The incoming water was abundant in quantity and lasted for a long duration. The thickness and flow rate of the density current were generally large. The monitoring in this study was focused on tracking the evolution process of the density current, and density current monitoring was primarily conducted at the $\mathrm{HH} 01, \mathrm{HH} 04$, and $\mathrm{HH} 07$ sections.

The thickness variation of the density current along the streamline at the sections HH01, HH04, and HH07 is shown in Figure 5. Density current was detected at 9:00 am on July 4, with its thickness increasing slowly with time. At the section HH01, the flow velocity at a single measuring point reached the maximum value of $2.04 \mathrm{~m} / \mathrm{s}$ at 3:00 pm on July 5, and the density current thickness reached the maximum value of $27.5 \mathrm{~m}$ at $3: 00 \mathrm{pm}$ on July 6 . The flow velocity at a single measuring point of the HH04 section reached the maximum value of $2.73 \mathrm{~m} / \mathrm{s}$ at $7: 45$ am on July 8 , with the maximum sediment thickness of $20.2 \mathrm{~m}$ appearing at 4:50 pm. At the HH06 section, the flow velocity at a single measuring point reached the maximum value of $2.73 \mathrm{~m} / \mathrm{s}$ at $12: 16 \mathrm{pm}$ on July 8 , concurrent with the maximum sediment thickness of 12.6 $\mathrm{m}$ at the same time. The maximum flow velocity at a single measuring point of the HH07 section was $2.99 \mathrm{~m} / \mathrm{s}$ at 7:00 am on July 8 whereas the maximum sedimentation thickness of $15.9 \mathrm{~m}$ was observed at $6: 42$ am on July 6 . As shown in Figure 4, which illustrates the characteristic values of the density current at each section during the density current monitoring period (July 4 to July 12), the maximum thickness of the density current in this study was $27.5 \mathrm{~m}$, appearing at the HH01 section on July 6 .

As shown in Figure 5, the density current could not be vented in time when it reached the dam, and owing to the blockage by the dam, the density current rose in height, thereby increasing the density current thickness before the dam and almost turning the reservoir into a fully turbid one, which accounted for the occurrence of the maximum thickness of $27.5 \mathrm{~m}$ on July 6 . With the continuous water input from the upstream, the density current formed backwater and rose in height at the HH01 section, resulting in an increase in the density current thickness. With the increase in water depth at the downstream sections of the plunging point, the flow velocity of density current was relatively reduced, but the thickness continued to increase, which allowed the density current to better transport sediment out of the reservoir.

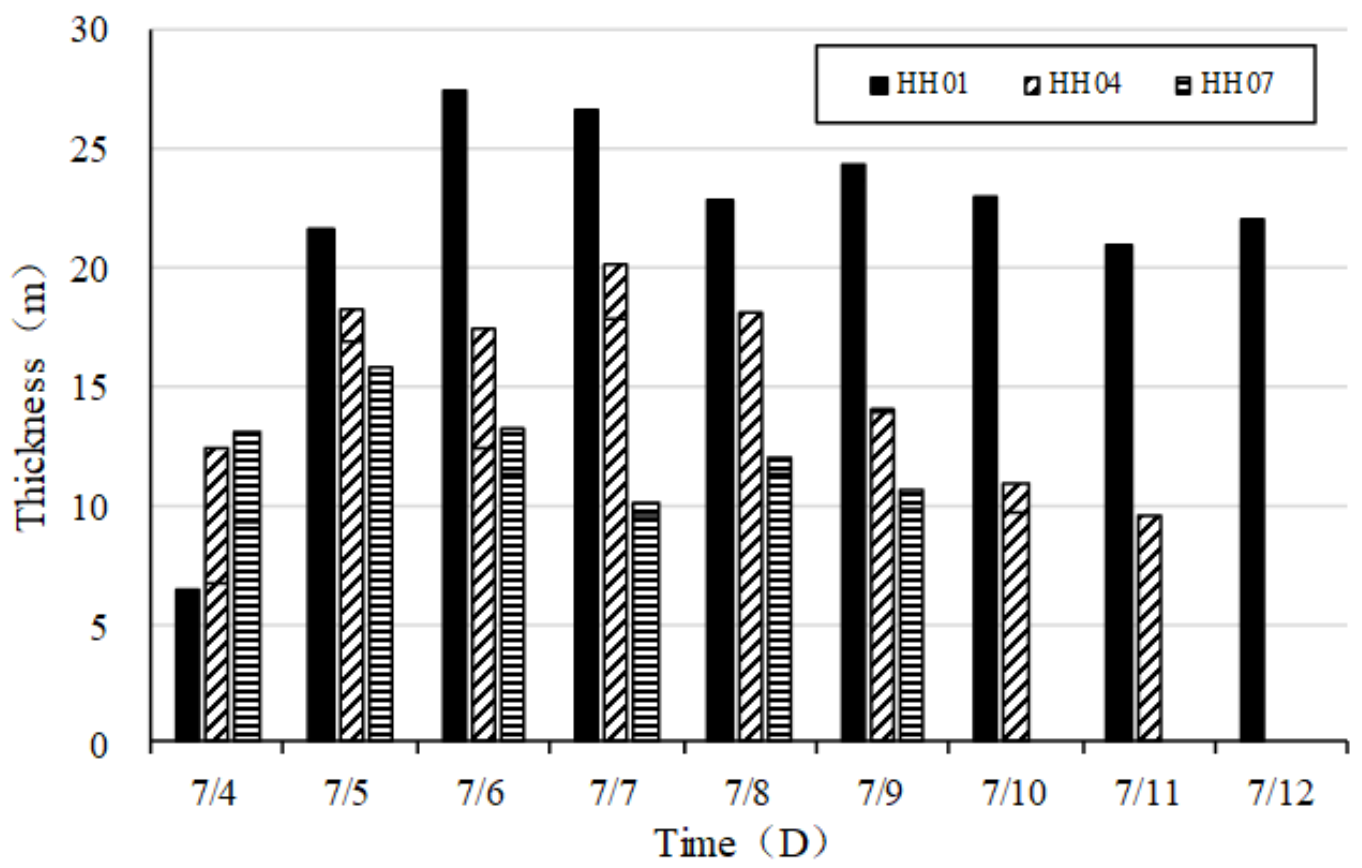

Fig. 5. Thickness variation of the density current along the streamline at the monitoring sections 
The variation of the mean velocity of the density current along the streamline at each monitoring section is shown in Figure 6, which indicates that it was a strong density current process with a short evolution time, and in particular, the density current in the downstream of $\mathrm{HH} 07$ had a high intensity with a large overall flow velocity. The maximum depth-averaged flow velocity of the density current appeared at the $\mathrm{HH} 07$ section, which was $1.69 \mathrm{~m} / \mathrm{s}$ and was relatively higher than the history data of this section.

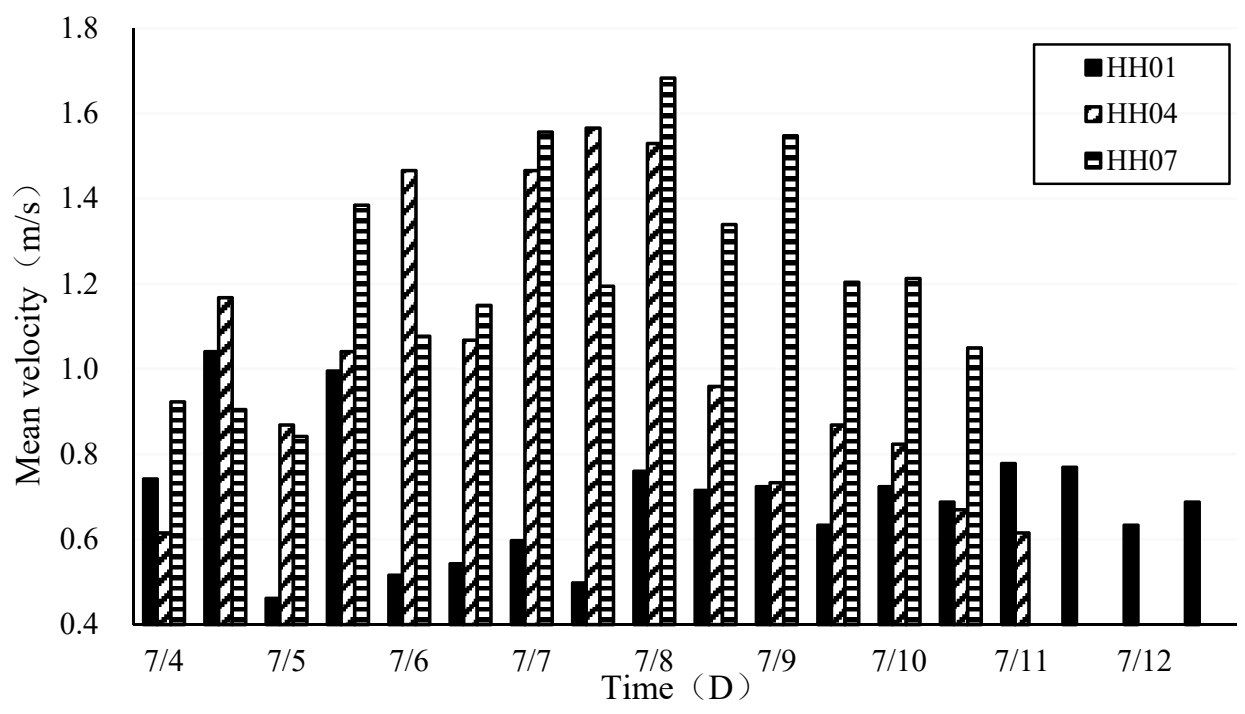

Fig. 6. Variation of the mean velocity of the density current along the streamline at each monitoring section

The HH01 section was close to the dam of the Xiaolangdi Reservoir, and therefore, the flow velocity at this section would be greatly affected by the opening and closing of the gates and sediment tunnels of the damduring the density current process in this study, the dam's discharge flow and sediment tunnels underwent changes several times. The flow velocity at the HH01 section was impacted by the gates and the incoming water from the upstream, and thereby fluctuated in intensity.

As indicated by the variation of average sediment concentration in the density current along the streamline at each monitoring section (Figure 7), the water level of the Xiaolangdi Reservoir was approximately $220 \mathrm{~m}$ during this density current process. Given that the plunging point was relatively close to the dam and that the river bed gradient was large after the plunging point, the discharge flow did not experience large resistance when moving forward, and hence, it did not lose much energy and still had a strong sediment transport capability, thereby allowing the average sediment concentration in the density current to fluctuate with the incoming water and sediment when the density current after the plunging point continued to propagate toward the dam.

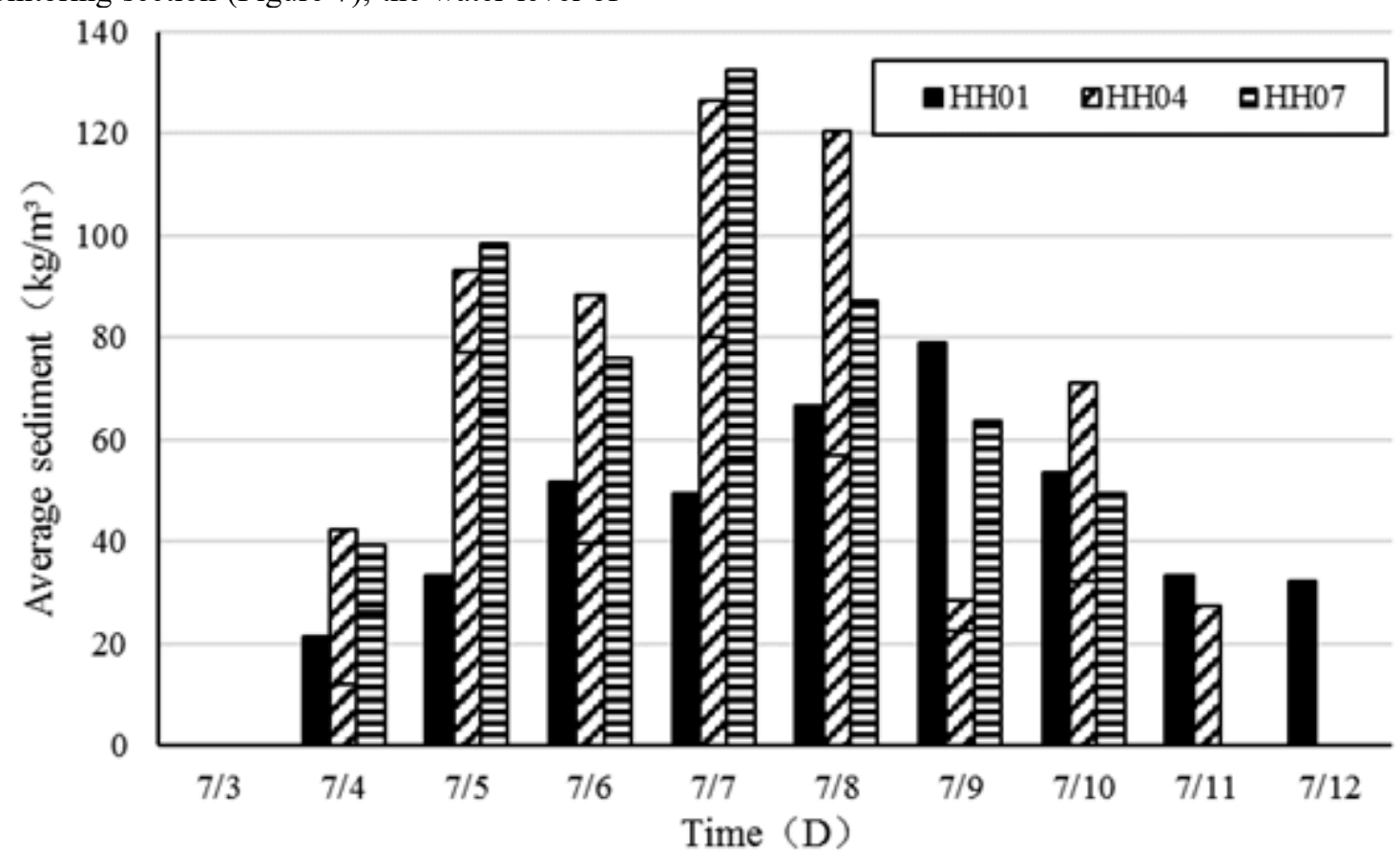

Fig. 7. Variation of the average sediment in the density current along the streamline at each monitoring section

\subsection{Evolution analysis of density current}


Based on theoretical analysis and the results of a water tank experiment, Fan et al. obtained the following formula for determining the plunging point of density current [10]:

$$
F r^{2}=\frac{V_{0}^{2}}{\eta_{g} g h_{0}}
$$

In the formula, $F r$ is the Froude number, and $V_{0}$ is the depth-averaged flow velocity in $\mathrm{m} / \mathrm{s} ; h_{0}$ is the vertical water depth in $\mathrm{m} ; \eta_{g}$ is the gravity correction coefficient, expressed as $\eta_{g}=\frac{\gamma^{\prime}-\gamma_{0}}{\gamma^{\prime}}$ where $\gamma^{\prime}$ is the volumetric weight of turbid water, $\gamma_{0}$ is the volumetric weight of clear water, $\gamma_{s}$ is the dry volumetric weight of sediment, and $\mathrm{S}$ is the sediment concentration in $\mathrm{kg} / \mathrm{m}^{3}$. When $\gamma_{s}=2650 \mathrm{~kg} / \mathrm{m}^{3}$, the formula can be re-written as [11] $\eta_{g}=\frac{\dot{\gamma}-\gamma_{0}}{\dot{\gamma}}=\frac{\left(\gamma_{s}-\gamma_{0}\right) S}{\left(\gamma_{s}-\gamma_{0}\right) S+\gamma_{0} \gamma_{s}}=\frac{1.65}{1.65+2650}=1 \frac{1}{1+S / 160}$

The Froude number of the plunging point was introduced to describe the hydraulic characteristics of the plunging region to use a corrected Froude number for determining the positions of the plunging point. Here, the Froude number represents the ratio of inertial force to gravity. When $F r>1$, it is a supercritical flow, and when $F r<1$, it is a subcritical flow.

Table 1. Calculated values of the plunging point in section $\mathrm{HH} 07$

\begin{tabular}{cccccc}
\hline Date & $\begin{array}{c}\text { Water } \\
\text { depth }(\mathrm{m})\end{array}$ & $\begin{array}{c}\text { Mean velocity of } \\
\text { density current }(\mathrm{m} / \mathrm{s})\end{array}$ & $\begin{array}{c}\text { Average sediment in } \\
\text { density current }\left(\mathrm{kg} / \mathrm{m}^{3}\right)\end{array}$ & $\begin{array}{c}\text { Density current } \\
\text { thickness }(\mathrm{m})\end{array}$ & Fr \\
\hline $7 / 4$ & 10.6 & 0.35 & 41.5 & 0.84 & 1.2 \\
$7 / 5$ & 9.1 & 0.85 & 26.1 & 9.32 & 4.1 \\
$7 / 6$ & 8.2 & 1.07 & 65.8 & 15.92 & 3.4 \\
$7 / 7$ & 7.3 & 1.56 & 84.2 & 13.27 & 4.6 \\
$7 / 8$ & 6 & 1.69 & 104.1 & 10.20 & 6.5 \\
$7 / 9$ & 5 & 1.56 & 71 & 12.24 & 7.0 \\
\hline
\end{tabular}

\subsection{Monitoring results of plunging point}

As sediment discharge from the Xiaolangdi Reservoir had already occurred at around 5:30 am on July 4, the onset of density current plunging was determined to be at 2:00 am on July 4.

At 8:20 am on July 4, the density current plunging point was detected at the water depth of $10.6 \mathrm{~m}$ at the HH07 section, with the maximum flow velocity reaching $0.39 \mathrm{~m} / \mathrm{s}$ and the maximum sediment concentration reaching $5.04 \mathrm{~kg} / \mathrm{m}^{3}$ at the plunging point. The mean velocity of the density current was $0.35 \mathrm{~m} / \mathrm{s}$, the average sediment concentration in the density current reached $4.12 \mathrm{~kg} / \mathrm{m}^{3}$, and the thickness of the density current reached $0.84 \mathrm{~m}$. At around 9:00 am on July 4, the thickness of the density current at the HH01 section was as high as $11.3 \mathrm{~m}$ and the maximum flow velocity at a single measuring point was $1.21 \mathrm{~m}^{3} / \mathrm{s}$.

During the density current period from July 4 to July 10 , the density current plunging point was located at the HH07 section; therefore, the HH07 section, also referred to as the plunging section, was subjected to full monitoring.
As the water level of the Xiaolangdi Reservoir decreased, the plunging point gradually moved downstream. On July 11, the point moved to the HH06 section, and on July 12, it reached the HH05 section.

As shown by the monitoring data and the plunging point discriminant formula, the thickness of the density current in the plunging region was closely related to the upstream flow rate.

\section{Longitudinal evolution of density current}

\subsection{Variation of density current thickness along the flow path}

We compiled the changes of density current thickness at the pre-dam monitoring sections on the monitoring dates after July 4 when turbid density current venting occurred, as shown in Figure 8. It was evident that the density current thickness increased along the flow path on each of the days, and the thickness at the HH01 section was greater to some extent than that at the HH04 section, which was due to the backwater generated by the moving density current when blocked by the dam. 


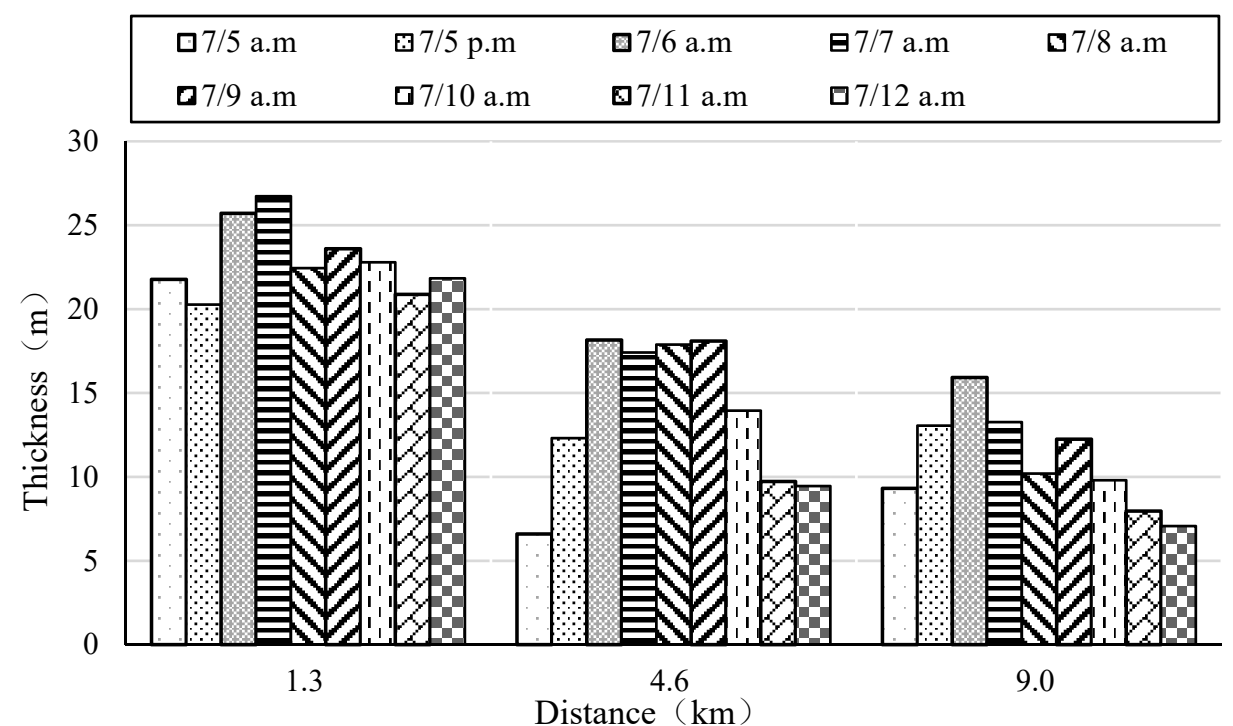

Fig. 8. Variation of density current thickness along the flow path

\subsection{Variation of mean velocity of the density current along the flow path}

As shown by the variation of mean velocity of the density current along the flow path in figure 9 , the mean velocity increased along the flow path in the region from the HH07 section to the pre-dam section as a result of the increase in river bed gradient along the flow path and the discharge of water out of the reservoir.

The mean velocity at each section along the flow path showed the following day-to-day variation characteristics: the mean velocity was the highest at each section from July 7 to the noon of July 9 but weak on July 5 when the density current monitoring was imitated and July 12 when the monitoring ended.

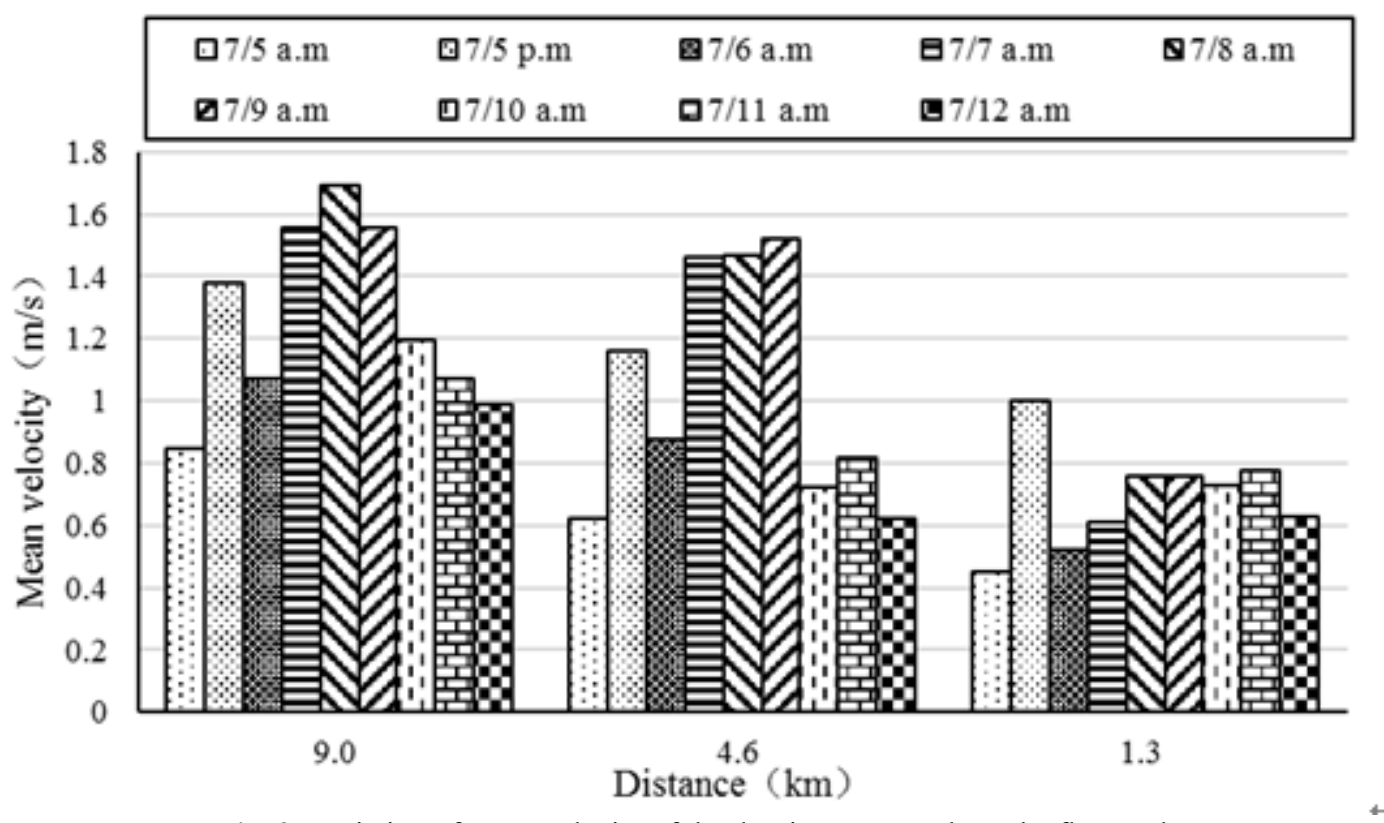

Fig. 9. Variation of mean velocity of the density current along the flow path

\subsection{Variation of average sediment concentration in the density current along the flow path}

The variation of average sediment concentration along the flow path is presented in Figure 10, which indicates that on July 4-the early stage of the density current - the sediment concentration was large at each section, which is attributed to the flushing of natural river sediment by the strong discharge flow out of the Sanmenxia Reservoir.
As the density current continued to develop, the average sediment concentration at each section tended to remain at the same level.

As shown by the variation plot, there was an increase in sediment concentration at the pre-dam section, which might be because, with the large discharge flow out of the Xiaolangdi Reservoir, the density current propagated downstream until it reached the dam, where the blockage by the dam caused the density current to form backwater, 
thereby increasing the density current thickness and leading to an increase in sediment concentration.

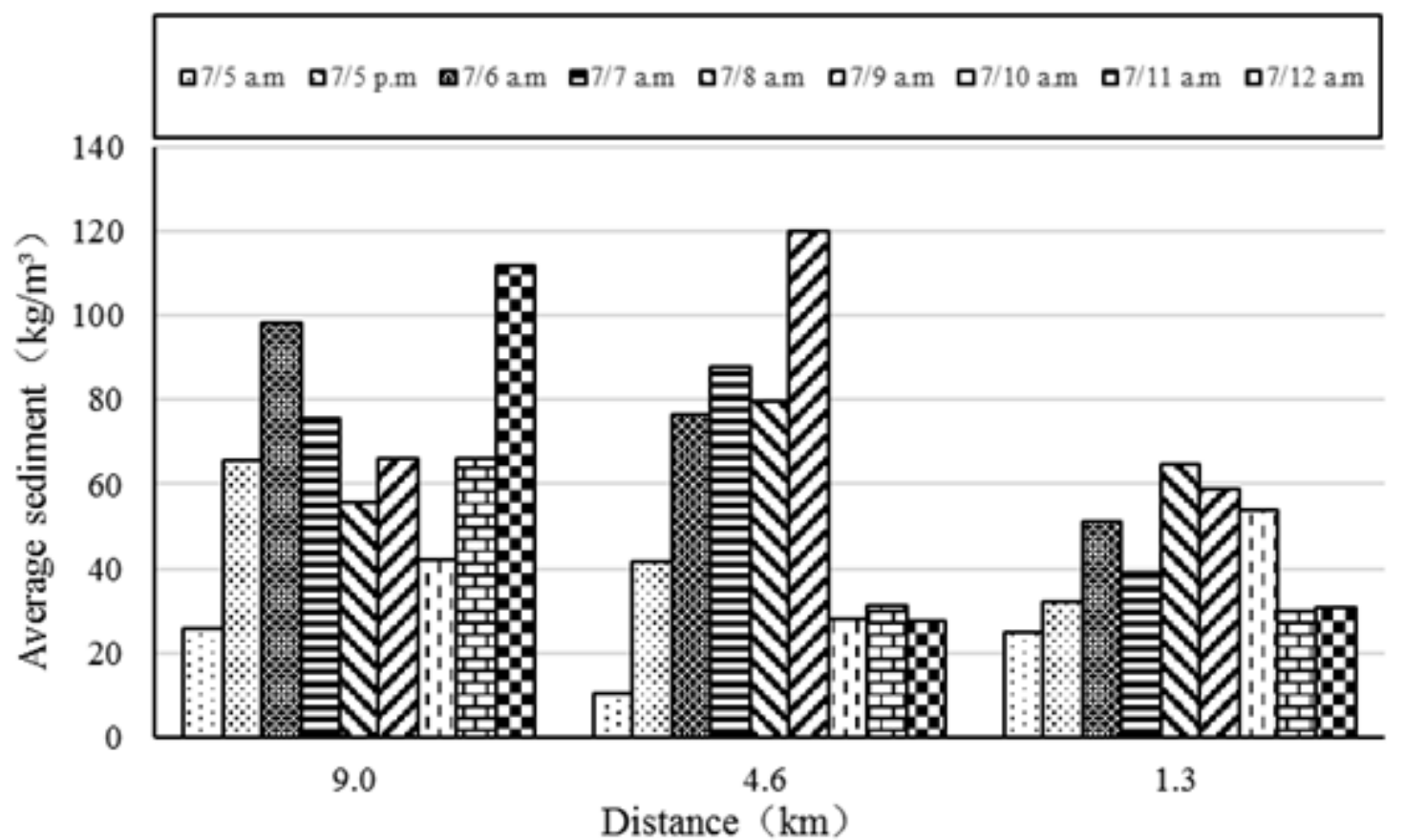

Fig. 10. Variation of average sediment in the density current along the flow path

\subsection{Pre-dam behavior of density current}

After the density current entered the reservoir at the plunging point, it propagated and reached the region before the dam, where backwater was formed and the density current became thicker with an increase in sediment concentration, and sediment-laden density current was eventually discharged out of the reservoir after the opening of sediment tunnels. During the evolution process, there was some sediment exchange between the density current and the clear water along the flow path, and the density current that had reached the pre-dam region was of great importance to the sediment discharge out of the reservoir. Therefore, it is particularly important to analyze the behavior and variation of the density current in the pre-dam region. The monitoring data of density current elevation and density current thickness at the HH01 section revealed that the density current had the same elevation in the lateral direction at this section, indicative of its homogeneous lateral distribution (figure 11).

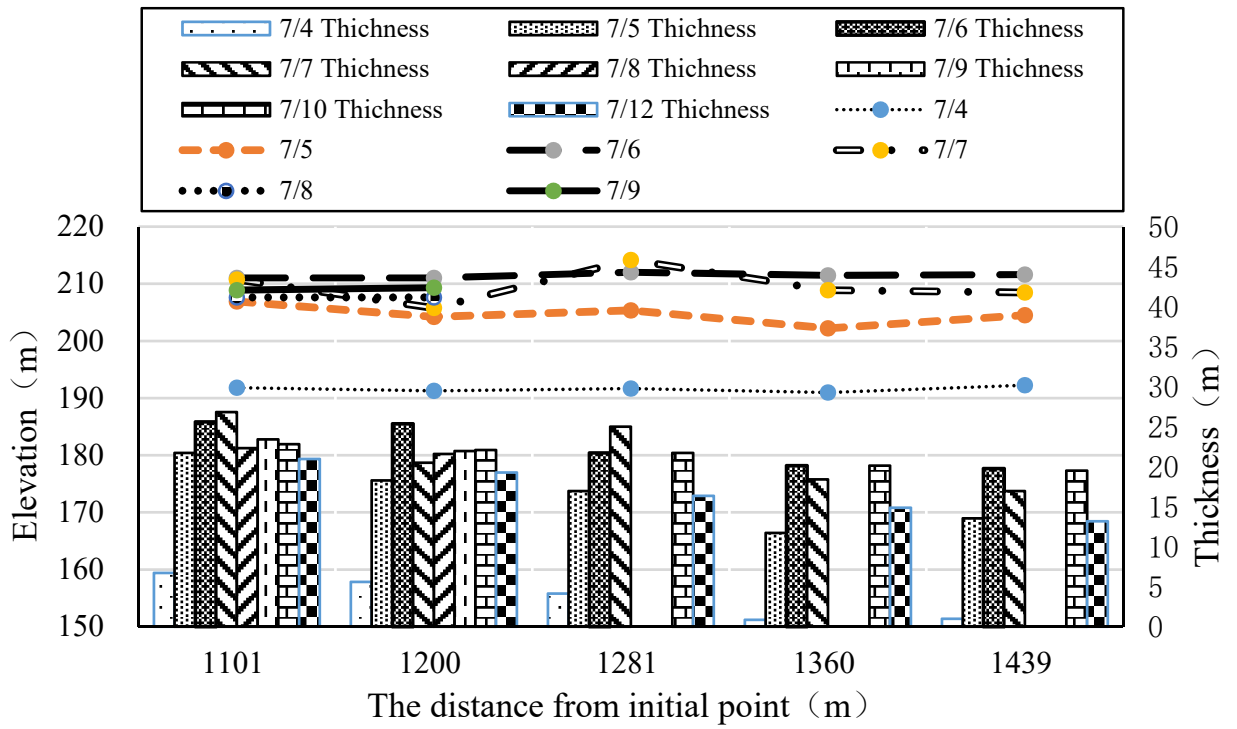

Fig. 11. Variation of elevation and density current thickness in section HH01

When density current was detected at 9:00 am at the HH01 section on July 4, its thickness along the streamline was $6.8 \mathrm{~m}$. However, the thickness tended to increase in the lateral direction on July 5 , with the maximum thickness reaching $21.7 \mathrm{~m}$. At the HH01 section, the maximum thickness of $27.5 \mathrm{~m}$ appeared at 3:00 pm on 
July 6 showing an increase of $20.7 \mathrm{~m}$ from the data of July 4 , and the elevation of the interface between the clear water and the turbid density current was increased by 22.2 $\mathrm{m}$ owing to backwater. The density current interface, on the whole, had an elevation of 191-214 m before the dam.

\section{Conclusions}

The reservoir scheduling experiment during this flood season successfully generated density current in the Xiaolangdi Reservoir. Based on the prototypical observation and data analysis, the following conclusions can be drawn:

(1) During the density current process, owing to the continuous decline of the water level in the Xiaolangdi Reservoir, the plunging point of the density current was close to the dam (HH07 section), and the flow velocity of the plunging density current was high. Given that the river bed gradient was above $2 \%$ in the region from the plunging point to the dam, the density current, once it plunged into the reservoir, would propagate rapidly, and the flow velocity would not decline significantly, thereby allowing the density current to transport the sediment out of the reservoir.

(2) With the large discharge flow out of the Xiaolangdi Reservoir, the density current moved to the dam, where it was blocked and formed backwater in front of the dam, thereby increasing the density current thickness and the sediment concentration.

(3) The variation of mean velocity of the density current along the flow path indicated that the mean velocity tended to increase with the flow path in the region from the $\mathrm{HH} 07$ section to the pre-dam section as a result of the increase in river bed gradient in this region and the discharge flow out of the reservoir.

(4) As shown by the variation of average sediment concentration along the flow path, the density current had a high sediment concentration at each section in the initial stage of the density current, which was attributed to the flushing of natural river sediment by the water discharged from the Sanmenxia Reservoir in the upstream direction. As the density current continue to develop, its average sediment concentration at each section tended to remain at the same level but was at a higher level at the pre-dam section.

(5) After entering the reservoir at the plunging point, the density current moved downstream and finally reached the pre-dam region, where backwater was formed to increase the density current thickness and the sediment concentration, and the density current was homogeneously distributed in the lateral direction. Given that the density current was laden with a high quality of sediment, the sediment discharge process would last for a longer time than that under normal conditions, which was beneficial to reservoir sediment discharge and could significantly increase the sediment discharge ratio.

These conclusions were based on the analysis of field monitoring data of the density current in the Xiaolangdi Reservoir in 2018. Given the limitation of the technology and equipment applicable for prototypical observation in the Xiaolangdi Reservoir in this study, further studies are required to provide a deeper insight into the law of movement of density current in this reservoir.

\section{Acknowledgements}

The authors wish to thank the anonymous reviewers for their constructive comments. We would like to thank Editage for English language editing.

Project Funding: National Research and Development Plan Key Item ( 2018YFC0407406-01 ) , National Science Fund Subsidized Item (51879115, 51509102, 51539004,51509103), Basic Research Special Business Fund of the Central Research Institute for Public Welfare Subsidized Item (HKY-JBYW-2016-26, HKY-JBYW2018-18)

\section{References}

1. L. Shujun, Yellow River, 38, 10, 137-141 (2016).

2. L. Guoying, Heilongjiang Water Resources, 9, 13 (2002).

3. L. Tao, T. Guangming, Z. Junhua, W. Yisheng, China Rural Water and Hydropower, 9, 21-24 (2006).

4. L. Shuxia, Z. Junhua, C. Shukui, M. Huaibao, J. Hydraul. Eng. 5, 567-572 (2006).

5. L. Shuxia, X. Junqiang, Z. Junhua, L. Peiqing, W. Yanping, Adv. Water Sci. 23, 03, 363-368 (2012).

6. Z. Junhua, C. Shukui, L. Shuxia, M. Huaibao, J. Hydraul. Eng. 9, 1085-1089 (2007).

7. H. Suzhen, J. Enze, L. Xiuzhi, W. Ping, J. Sediment Res. 5, 46-50 (2004).

8. L. Xiangyang, X. Lixiang, X. Zanqi, et al. J. Water Res. Water Eng. 6, 163-167 (2017).

9. S. Dongpo, W. Moxi, Journal of North China University of Water Resources and Electric Power (Natural Science Edition), 2, (2018).

10. F. Jiahua, J. Hydraul. Eng. 42, 1, 19-26 (2011).

11. L. Tao, X. Junqiang, Z. Junhua, G. Guoming, X. Runliang, W. Zhanwei, W. Zenghui, Adv. Eng. Sci. 49, 2, 62-68 (2017). 